\title{
Uso da ouvidoria como ferramenta de gestão dos serviços odontológicos no município do Recife
}

\section{Use of the ombudsman as a management tool for dental services in the city of Recife}

\section{Uso del defensoría como herramienta de gestión para servicios dentales em Recife}

Gabriela de Nazaré Wanderley Lira ${ }^{1}$ Ive da Silva Monteiro ${ }^{1}$ Maria Cristina Reis Tavares ${ }^{1}$

RESUMO: A ouvidoria estabelece um canal prático e de fácil acesso aos usuários do serviço público, ao mesmo tempo que induz, nas instituições, práticas de análises e avaliações dos procedimentos de trabalho a partir das percepções dos usuários. Então, objetivou-se identificar o fluxo das demandas recebidas pela Ouvidoria SUS Recife, o perfil dos demandantes e das demandas, e como esse instrumento é utilizado para gestão dos serviços odontológicos do município. Realizou-se um estudo descritivo, quali-quantitativo, submetendo-se dados da Ouvidoria SUS Recife de 2008 a 2017 à estatística descritiva e dados obtidos em grupo focal com cinco coordenadores de saúde bucal do município à análise de conteúdo na modalidade temática de Bardin.Identificou-se um desconhecimento dos entrevistados sobre o fluxo instalado na Ouvidoria SUS Recife, evidenciando fragilidade de comunicação e articulação entre a ouvidoria e os gestores de saúde bucal do município. Das 820 demandas analisadas, constatou-se que mulheres de 40-49 anos, com ensino fundamental completo, compõem o principal perfil dos demandantes da Ouvidoria SUS Recife. Das demandas, 75,2\% foram reclamações, sendo recursos humanos o assunto mais citado (36,1\%). A maior potencialidade da ouvidoriaidentificada pelos gestores foi representada pela visibilidade que ela promove das demandas da sociedade, subsidiando a tomada de decisão dos gestorespara aprimorar os serviços. Entretanto, a ouvidoria ainda ésubutilizada pelos cidadãos, o que compromete o uso potencial da ouvidoria como uma ferramenta de gestão.

Palavras Chaves: Participação social. Defesado paciente. Administração em saúde.

1 Secretaria de Saúde do Recife

ISSN 1982-8829 Tempus, actas de saúde colet, Brasília, 13(3), 43-59, set, 2019. Epub Jul/2020 
ABSTRACT: The ombudsman establishes a practical channel for public service users, while induces practices of analysis and evaluation of work procedures based on users' perceptions. The aim was to identify the flow of the demands received by SUS Recife Ombudsman, the profile of the claimants, the demands, and how this instrument is used to manage the dental services of the municipality. A descriptive, qualitative-quantitative study was carried out, submitting data from the SUS Recife Ombudsman from 2008 to 2017 to descriptive statistics and data obtained from a focal group with five oral health coordinators from the municipality to content analysisof the thematic modality of Bardin. It was identified a lack of knowledge of respondents about the flow installed in the SUS Recife Ombudsman, showing weakness of communication and articulation between the ombudsman and the oral health managers of the municipality. Of the 820 demands analyzed, women aged 40-49, with complete elementary education, make up the main profile of the SUS Recife Ombudsman. Of the demands, $75.2 \%$ were complaints, with human resources being the most cited subject (36.1\%). The greater potential of the ombudsman identified by managers was represented by the visibility it promotes of society's demands, supporting managers' decisionmaking to improve services. However, the ombudsman is still underutilized by citizens, which compromises the potential use of the ombudsman as a management tool.

Key Words: Social participation. Patient advocacy. Health administration.

RESUMEN: El Defensoría establece un canal práctico y de fácil acceso para los usuarios del servicio público y induce, en las instituciones, prácticas de análisis y evaluación de los procedimientos de trabajo desde las percepciones de los usuarios. El objetivo del estudio fue identificar el flujo de demandas recibidas por el Defensoría del SUS Recife, el perfil de los demandantes y las demandas, y cómo se utiliza este instrumento para la gestión de los servicios dentales del municipio. Se realizó un estudio descriptivo, cualitativo y cuantitativo, presentando datos del Defensoría del SUS Recife de 2008 a 2017 a estadísticas descriptivas y datos de un grupo focal con cinco coordinadores de salud oral para el análisis de contenidomodalidad temática de Bardin. Se identificó una falta de conocimiento de los encuestados sobre el flujo instalado en el Defensoría, muestrando debilidad en la comunicación y la articulación entre el defensoría y los gerentes. De las 820 demandas analizadas, las mujeres de 40 a 49 años, con educación primaria completa, conforman el perfil principal de los acusados del Defensoría del SUS Recife. De las demandas, 75.2\% fueron quejas, siendo los recursos humanos el tema más citado (36.1\%). El mayor potencial del defensoría identificado por los gerentes estuvo representado por la visibilidad que promueve de las demandas de la sociedad, apoyando la toma de decisiones de los gerentes para mejorar los servicios. Sin embargo, el defensoría todavía está infrautilizado por los ciudadanos, lo que compromete el uso potencial del defensoría como herramienta de gestión.

Palabras clave: Participación social. Defesa del paciente. Administración en salud. 


\section{INTRODUÇÃO}

A participação popular e o controle social em saúde, dentre os princípios do Sistema Único de Saúde (SUS), destacam-se como de relevância social e política, pois se constituem na garantia de que a população envolver-se-á no processo de formulação e controle das políticas públicas de saúde. No Brasil, controle social se refere à participação da comunidade no processo decisório sobre políticas públicas e ao controle sobre a ação do Estado ${ }^{1}$. Como subsídios para colocar em prática o controle social, tem-se como marcoo desenvolvimento de mecanismos diretos de participação coletiva dos usuários dos serviços públicos de saúde, como as Conferências e os Conselhos de Saúde nas três esferas de governo, e mecanismos de participação individual, como as ouvidorias ${ }^{2}$.

Um importante marco foi a instituição, por meio do Decreto $n^{\circ} 4.726$, de 9 de junho de 2003, da Secretaria de Gestão Estratégica e Participativa do Ministério da Saúde (SEGESP/MS). E, no âmbito dela, do Departamento de Ouvidoria Geral do SUS (DOGES), com o objetivo de propor, coordenar e implementar a Política Nacional de Ouvidoria em Saúde no âmbito do SUS, buscando integrar e estimular práticas que ampliem o acesso dos usuários ao processo de avaliação das ações e serviços públicos de saúde. A relevância da ouvidoria também é mostrada na Política Nacional de Humanização, que preconiza a avaliação pelo usuário por meio de pesquisas de satisfação, presença de ouvidoria e sua participação em instâncias de gestão ${ }^{3}$.

Ressalta-se que as demandas à ouvidoria podem ter diversos motivos, dentre os quais, pedidos de informações e esclarecimentos sobre dúvidas (os quais normalmente não geram registros da demanda), reclamações, elogios, denúncias, sugestões e solicitações ${ }^{4}$.

É papel da ouvidoria efetuar o encaminhamento, a orientação, o acompanhamento da demanda e a resposta ao usuário, visando propiciar uma resolução adequada aos problemas apresentados, de acordo com os princípios e diretrizes do $\mathrm{SUS}^{4}$. Dessa forma, uma manifestação pode culminar, se bem trabalhada, na solução de problemas coletivos e no aprimoramento dos serviços de saúde para toda a população.

O serviço de ouvidoria estabelece um canal prático e de fácil acesso aos usuários do serviço público. Tem como função principal controlar o funcionamento da administração pública, denunciando eventuais falhas e difundindo os princípios da justiça entre os cidadãos $^{2}$, além de identificar e induzir, nas instituições, as práticas de análises e avaliações dos procedimentos de trabalho a partir das percepções dos usuários dos serviços ofertados 5 .

Como diretrizes, a Ouvidoria de Saúde tem: ampliar a participação dos cidadãos usuários do SUS, garantindo-se a escuta, análise e o retorno das demandas dos cidadãos; criar um canal direto de comunicação e escuta que tenha como características a independência, autonomia e ética do sistema, preservando-se o sigilo que a atividade requer; e possibilitar a avaliação contínua da qualidade dos serviços prestados pelo SUS ${ }^{6}$.

ISSN 1982-8829 Tempus, actas de saúde colet, Brasília, 13(3), 43-59, set, 2019. Epub Jul/2020 
No Recife, a decisão pela implantação da Ouvidoria Municipal de Saúde foi dada durante a realização da VII Conferência Municipal de Saúde, em 20057. Após essa decisão, em 22 de dezembro de 2006, entrou em vigor a Lei n 17.281, que instituiu sua Ouvidoria Municipal de Saúde (Ouvidoria SUS Recife). É importante salientar que Recife foi escolhido pelo DOGES/SEGEP/ MS para realizar o Projeto Piloto de descentralização do Sistema Informativo OuvidorSUS ${ }^{8}$. A Ouvidoria SUS Recife conta com uma equipe composta por gestor, coordenador, supervisor de tele atendimento, técnico de análise de demandas e tele atendentes. Soma-se a essa equipe, uma rede formada por 30 interlocutores distribuídos entre Policlínica/Hospital/Centro Médico, Gerências Gerais, Distritos Sanitários, Secretarias Executivas, Maternidades Municipais, Gabinete, Laboratório, Centro de Vigilância Ambiental (CVA) e Serviço de Atendimento Móvel de Urgência $(\mathrm{SAMU})^{9}$.

A Ouvidoria SUS Recife recebe demandas acerca de toda a rede municipal de saúde que, de acordo com o Plano Municipal de Saúde do Recife ${ }^{10}$, é composta por: 130 unidades de Saúde da Família (USF); 12 policlínicas; 9 Centros de Especialidades Odontológicas (CEO); 1 laboratório municipal de Saúde Pública; 9 unidades especializadas, 3 hospitais municipais; 4 serviços de pronto atendimento (SPA); 11 farmácias da família; 11 Centros de Assistência Psicossocial (CAPS) e 3 maternidades, distribuídos entre os 8 Distritos Sanitários do município. Além da rede complementar que conta com 3 hospitais gerais; 1 hospital pediátrico; 5 laboratórios de patologia; 8 serviços de imagem; 4 clínicas oftalmológicas; e 7 centros de reabilitação. A ouvidoria atende demandas de todos esses pontos da rede municipal de atenção à saúde e as relacionadas à vigilância em saúde, em especial à Vigilância Sanitária. O contato com a ouvidoria pode ser realizado através de 6 canais de comunicação: tele atendimento; formulário web; e-mail; atendimento presencial; cartas/ofícios, comunicação de outros órgãos com a ouvidoria; e caixas de sugestão disponíveis em algumas unidades de saúde?

Diante da importância da ouvidoria para o exercício do controle social e melhoria dos serviços públicos, além da carência de estudos, especialmente no âmbito da saúde bucal,que avaliem como os dados recebidos pela Ouvidoria influenciam o planejamento e tomada de decisão por parte dos gestores, esse artigo objetivou identificar o fluxo das demandas recebidas pela Ouvidoria SUS Recife, o perfil dos demandantes e demandas, e como esse instrumento é utilizado para gestão dos serviços odontológicos do município.

\section{MÉTODO}

Trata-se de um estudo com abordagem quali-quantitativa, desenvolvido a partir da análise de dados secundários da Ouvidoria SUS Recife e dados primários obtidos em grupo focal realizado com coordenadores de saúde bucal do município de Recife.

Para a parte quantitativa do estudo, coletaram-sedados secundários dobanco de dadosgerencialinternoda Ouvidoria SUS Recife referentes a todas as demandas recebidas por 
elasobre assistência odontológica prestada no município entre 2008 (ano em que foi inaugurada a Ouvidoria SUS Recife) e 2017. Dessas, consideraram-seos dados relacionados ao perfil do demandante (sexo, escolaridade e faixa etária),classificação e motivo das manifestações. Taisdados foram processados no software Epi Info ${ }^{\mathrm{TM}}$ versão 7.2 e submetidos à análise estatística descritiva (distribuição de frequência), com apresentação em gráfico e tabelas.

Para a parte qualitativa do estudo, a coleta de dados foi realizada por meio de um grupo focal com 4 coordenadores distritais de saúde bucal e 1 integrante da coordenação municipal de saúde bucal, cuja média de tempo em exercício dessas funções era de 1 ano e 2 meses no momento da pesquisa. Ressalta-se, entretanto, que todos os coordenadores distritais $(n=6)$ e municipais $(n=3)$ de saúde bucal em exercício no ano de 2017 foram convidados a participarem deste grupo focal previamente agendado com eles.

O grupo focal foi coordenado por um moderador, auxiliado por dois observadores que se responsabilizaram pela gravação em áudio digital da entrevista e anotaçãodas principais impressões verbais e não verbais. Utilizou-se um roteiro semiestruturado, com sete perguntas norteadoras, tendo como questão central "Quais experiências vocês vivenciaram/vivenciam, enquanto gestor de saúde bucal, a partir de demandas da Ouvidoria?". Toda a entrevista foi gravada, apresentando uma duração aproximada de 90 minutos. Após transcrita na íntegra, submeteram-se as falas obtidas à análise de conteúdo na modalidade temática baseada em Bardin ${ }^{11}$, seguindo as três etapas: préanálise, exploração do material com a escolha das categorias de eixos temáticos para análise dos dados, e o tratamento dos resultados com inferências e interpretações. Para preservar o anonimato dosparticipantes, os fragmentos de fala reproduzidos adiante estão identificados pela letra " $\mathrm{C}$ " de coordenador, seguida do número de entrada do participante no estudo.

Este trabalho foi realizado em conformidade à Resolução no 466/2012 do Conselho Nacional de Saúde e aprovado pelo Comitê de Ética em Pesquisa do Hospital Otávio de Freitas, sob parecer $\mathrm{n}^{\mathrm{o}}$. 2.525.459. Todos os participantes assinaram previamente o Termo de Consentimento Livre e Esclarecido.

\section{RESULTADOS E DISCUSSÃO}

No período de 2008 a 2017 a Ouvidoria Municipal de Saúde do Recife recebeu um total de 72.562 demandas.Destas, 820 relacionaram-se ao assunto "Assistência Odontológica" o que representou $1,13 \%$ das demandas totais. Os anos de 2014 e 2017 foram responsáveis pelo maior número de demandas relacionadas à assistência odontológica prestada no município (Gráfico 1).

Gráfico 1.Distribuição das demandas relacionadas à assistência odontológica em comparação com o total de demandas recebidas pela Ouvidoria SUS Recife por ano, no período de 2008 a 2017 - Recife, 2019. 
Fonte: Base de dados da Ouvidoria Municipal de Saúde do Recife

Os resultados e discussão deste estudo foram divididos em 4 tópicosde acordo com os dados sobre o perfil dos demandantes e das demandas relacionadas à saúde bucal obtidos no banco de dados daOuvidoria SUS Recife e fragmentos de falas de três categorias de eixos temáticos que emergiram da análise de conteúdo (desconhecimento do fluxo das demandas da ouvidoria,identificação das demandas da ouvidoria sobre saúde bucal, ouvidoria como ferramenta de gestão).

\section{Fluxo da demanda}

Ao ser recebida uma demanda pela ouvidoria, a manifestação é inserida no sistema desenvolvido pelo Ministério da Saúde, OuvidorSUS, e o cidadão recebe um número de protocolo para fazer o acompanhamento. A demanda é então analisada por técnico da ouvidoria, que realiza a tipificação da mesma, a fim de categorizar as manifestações acolhidas de acordo com seu assunto. Isso possibilita o agrupamento das demandas por categorias, análise de dados e a elaboração de relatórios gerenciais sobre diversos assuntos ${ }^{12}$.

Após tipificação, a demanda é encaminhada ao interlocutor responsável, via sistema OuvidorSUS, que recebe e identifica a área/setor responsável pela resolutividade do caso, encaminhando-a com definição do prazo. Atualmente, segundo a Lei n ${ }^{\circ} 13.460$ de 26 de julho de 2017, a ouvidoria deverá encaminhar a decisão administrativa final ao usuário, observado o prazo de trinta dias, prorrogável de forma justificada uma única vez, por igual período ${ }^{13}$.

Ao tomar conhecimento, o setor responsável apura, atende e dá resposta à manifestação. $\mathrm{O}$ interlocutor recebe a resposta e devolve à ouvidoria, que a analisa e, considerando-a satisfatória, dá por encerrada a manifestação. Caso não seja considerada satisfatória, a ouvidoria poderá solicitar informações e esclarecimentos diretamente a agentes públicos do órgão ou entidade a que se vincula, devendo as solicitações serem respondidas no prazo de vinte dias, prorrogável de forma justificada uma única vez, por igual período ${ }^{13}$. A resposta fica disponível ao cidadão, através do número de protocolo, informado ao cidadão após registro da manifestação, no site da prefeitura, via telefone ou email.

O desconhecimento acerca desse fluxo instalado na Ouvidoria SUS Recife, desde o recebimento da demanda até sua resposta pelo setor responsável foi relatada pelos entrevistados, evidenciando uma fragilidade de comunicação e articulação entre a ouvidoria e os gestores de saúde bucal do município:

"[...] eu não consigo visualizar o desenho da ouvidoria daqui. [...] Nunca chegou ao nosso conhecimento formalmente"(C.2).

“[...] uma dificuldade que eu tenho é entender o fluxo da ouvidoria. [...] eu queria saber qual o 
tempo especificamente que a gente tem para responder a demanda. Realmente eu não sei se a gente tem um prazo para responder aquela questão"(C.1).

Para que os objetivos da ouvidoria sejam realmente alcançados, é necessário que haja uma integração entre os setores internos e externos de toda administração pública, possibilitando a obtenção de respostas precisas e sistematizadas ${ }^{14}$. Dessa forma, fica explícita a necessidade de se construir, nas organizações públicas, uma visão sistêmica das dimensões organizacionais de forma a alcançar integração e harmonia entre as diversas dimensões. O conhecimento acerca do fluxo das demandas tem suma importância, pois colabora na transformação das organizações públicas de forma permanente para que se tornem mais ágeis, propiciando um serviço público de melhor qualidade e que vá ao encontro dos anseios da sociedade ${ }^{15}$.

\section{Perfil do Demandante}

Os dados disponíveis sobre perfil do demandante referem-se ao período de 2009 (quando as variáveis relacionadas ao perfil do demandante como sexo, escolaridade e faixa etária foram acrescentadas ao banco de dados após a criação do formulário pelo FORMSUS, que é um serviço oferecido pelo DATASUS para criação de formulários web) ao ano de 2017.Assim, foi possível acessar dados socioeconômicos de 772 usuários que procuraram o serviço da Ouvidoria SUS Recifecom demandas relacionadas à assistência odontológica nesse período.

De acordo com o banco de dados da Ouvidoria SUS Recife, os demandantes são majoritariamente do sexo feminino (Tabela 1). Esse maior número de demandas realizadas pelo sexo feminino assemelha-se ao encontrado em outros estudos e relatórios de ouvidorias do SUS ${ }^{16,17,18,19,20}$.

Ribeiroet al. (2006) ${ }^{21}$ traçaram o perfil sociodemográfico dos usuários do SUS, constatando que, dentre os indivíduos atendidos, há o predomínio de mulheres sobre homens, em uma proporção de 2:1. Isso pode ser explicado pelo fato de desempenharem um papel mais ativo no tratamento à saúde e perceberem mais facilmente os riscos à saúde do que os homens ${ }^{22,23}$. Assim, é esperado que as mulheres também sejam maioria em relação a realização de manifestações à ouvidoria de saúde.

Interessante observar que a faixa etária de 30 a 49 anos corresponde a 49,1\% das demandas. A maior frequência desse grupo também foi encontrada em outros estudos ${ }^{24,25,26}$. A alta frequência de doenças crônicas nessa faixa etária ${ }^{26,27}$ pode explicar a maior procura por atendimentos nos serviços de saúde nesse intervalo de idade e, juntando o fato de que essa é uma população economicamente ativa, a dificuldade de acesso aos serviços pode também ser um fator de insatisfação. Em relação à assistência odontológica, também nessa faixa etária, temos doenças bucais como cárie e doença periodontal mais prevalentes, e que demandam um tratamento mais especializado ${ }^{28,29,30}$. Diante disso, a dificuldade de acesso a esse tratamento mais complexo pode gerar mais insatisfação e, com isso, mais demandas à ouvidoria.

ISSN 1982-8829 Tempus, actas de saúde colet, Brasília, 13(3), 43-59, set, 2019. Epub Jul/2020 


\begin{tabular}{|c|c|c|}
\hline Variáveis & $\mathrm{n}$ & $\%$ \\
\hline Sexo & & \\
\hline Feminino & 548 & 71,0 \\
\hline Masculino & 208 & 26,9 \\
\hline Não identificado & 16 & 2,1 \\
\hline Faixa Etária & & \\
\hline Até 19 anos & 11 & 1.4 \\
\hline 20 a 29 & 97 & 12.6 \\
\hline 30 a 39 & 180 & 23.3 \\
\hline 40 a 49 & 199 & 25,8 \\
\hline 50 a 59 & 109 & 14.1 \\
\hline 60 a 69 & 67 & 8.7 \\
\hline 70 ou mais & 13 & 1.7 \\
\hline Sem informação & 96 & 12.4 \\
\hline Escolaridade & & \\
\hline Não sabe ler/escrever & 8 & 1,0 \\
\hline Alfabetizado & 79 & 10,2 \\
\hline Ensino Fundamental completo & 125 & 16,2 \\
\hline Ensino Médio completo & 387 & 50,1 \\
\hline Ensino Superior completo & 58 & 7.5 \\
\hline Sem Informacão & 115 & 14.9 \\
\hline
\end{tabular}

Fonte: Base de dados da Ouvidoria Municipal de Saúde do Recife

Em relação à escolaridade, embora estudos anteriores tenham apontado que usuários dos serviços de saúde possuíam, em sua maioria, o ensino fundamental incompleto ${ }^{21,31,32}$, nessa pesquisa aproximadamente $3 / 4$ dos demandantes declararam que possuem, no mínimo, o ensino fundamental completo $(73,83 \%)$. Esse referido aumento da escolaridade dentre os usuários da Ouvidoria SUS Recife pode estar relacionado ao aumento da população SUS-dependente no Brasil, que de acordo com a Pesquisa Nacional de Saúde, realizada em 2013, era de aproximadamente $80 \%$ da população ${ }^{33}$. Além disso, essa análise do nível de escolaridade dos reclamantes evidencia que o acesso à ouvidoria ainda está restrito à população com melhores condições de estudo e, consequentemente, com mais acesso a informações e aos canais de participação do governo ${ }^{34}$.

\section{Classificação e Motivo das Manifestações}

De acordo com o item classificação do 'Manual de Tipificação do OuvidorSUS', denúncia é toda manifestação que indica irregularidade, ou indícios, na administração e no atendimento, seja em entidade pública ou privada. A reclamação é um relato de insatisfação com ações e/ou serviços de saúde, sem, contudo, ter o caráter de requerimento. Essa dimensão de requerimento transforma a manifestação em uma solicitação. Por informação, o manual dispõe ser o questionamento que 
se faz sobre o sistema ou assistência de saúde. O elogio consiste na manifestação do cidadão, de satisfação ou agradecimento por serviços prestados pelo SUS. A sugestão, por sua vez, é a manifestação que propõe algum tipo de ação destinada à melhoria do SUS ${ }^{12}$.

Os dados analisados demonstram que as manifestações acolhidas no período do estudo são majoritariamente reclamações, seguidas pelas solicitações. Já as sugestões ficaram em último lugar com apenas duas manifestações (Tabela 2).

\begin{tabular}{|c|c|c|}
\hline Variáveis & $\mathrm{n}$ & $\%$ \\
\hline \multicolumn{3}{|l|}{ Classificação } \\
\hline Reclamacão & 617 & 75.2 \\
\hline Solicitacão & 155 & 18.9 \\
\hline Denúncia & 23 & 2,8 \\
\hline Elogio & 15 & 1.8 \\
\hline Sugestão & 2 & 0.2 \\
\hline Informação & 8 & 1,0 \\
\hline \multicolumn{3}{|l|}{ Assunto } \\
\hline Assistência Básica & 64 & 7.8 \\
\hline Assistência especializada & 87 & 10,6 \\
\hline Atendimento & 20 & 2.4 \\
\hline Estabelecimento de saúde bucal & 89 & 10,9 \\
\hline Infra-Estrutura do Consultório & 1 & 0,1 \\
\hline Recursos humanos & 296 & 36.1 \\
\hline Recursos materiais & 237 & 28.9 \\
\hline Outros & 26 & 3,3 \\
\hline
\end{tabular}

Fonte: Base de dados da Ouvidoria Municipal de Saúde do Recife

Tem-se que as reclamações são manifestações frequentes na ouvidoria e, por refletir a insatisfação do cidadão, devem ser analisadas cuidadosamente pelos gestores ${ }^{35}$. De fato, à exceção dos elogios, em cada manifestação existe uma reclamação implícita, e são manifestações facilmente esperadas e justificadas, pois faz parte da cultura da nossa sociedade reclamar mais do que elogiar ${ }^{14}$.

“[...] o usuário usa muito mais [a ouvidoria] para fazer críticas do que em busca da melhoria mesmo do que é ofertado [...] geralmente é para criticar a gestão" (C.4).

Deve-se perceber que, em cada crítica ou reclamação recebida pelo gestor há sempre uma solicitação implícita de melhoria dos serviços que são ofertados, e quanto menos são levadas em consideração na gestão dos serviços, a população se sente negligenciada, configurando uma situação de descaso, enfraquecendo assim, o processo de cidadania ${ }^{36}$. Por isso, diante dessa situação, a reflexão e análise cuidadosa dessas demandas devem ser realizadas pelos gestores, o que não se 
identifica no fragmento de fala acima.

Em relação ao item assunto, que informa qual o motivo da demanda, identificaram-se 14 motivos distintos, sendo recursos humanos o mais citado. Recursos materiais vieram logo após e, por último, os sub assuntos credenciamento de CEO e infraestrutura do consultório, ambos com 1 $(0,1 \%)$ registro apenas.

Para os gestores, ao abordarem os recursos humanos como o motivo mais frequente das demandas recebidas pela Ouvidoria SUS Recife, eles especificam que:

"[...] a maioria é falta de profissional, falta de dentista"(C.3).

"Demora na marcação, principalmente na endodontia [...] e o profissional não atender, por algum motivo, $[. .$.$] mudança de horário ou está faltando algum insumo"(C.5).$

“Falta de profissional ou não atendimento do paciente"(C.1).

“Geralmente é a falta de profissional e, a maioria das vezes também, algumas que eu vejo... foi a quantidade de oferta de serviços na especialidade, principalmente endodontia"(C.4).

Tais relatos permite observar que as situações-problemas percebidas pelos gestores de saúde bucal correspondem àquelas percebidas na assistência pelos usuários do serviço e que geram demandas à ouvidoria. Os assuntos relacionados aos recursos humanos e materiais registrados no Ouvidoria SUS Recife estão detalhados na Tabela 3.

Alguns autores afirmam que, no Brasil, ainda é comum o pensamento, entre os usuários do SUS de que aquele serviço oferecido é um favor e, por isso, nem sempre consideram relevante o desgaste estrutural ou a má conservação dos estabelecimentos ${ }^{36,37}$. É tanto que, dentre as 820 demandas, apenas uma teve como assunto a infraestrutura do consultório e 89 o estabelecimento de saúde bucal. Já o cumprimento da carga horária, presença constante de profissionais nos estabelecimentos, facilidade na obtenção de medicamentos, e no acesso aos serviços, por interferirem na realização do atendimento, são muito mais valorizados pelos usuários e, por isso, há uma maior manifestação sobre esses assuntos ${ }^{37}$.

\begin{tabular}{|l|c|c|}
\hline Tabela 3. Frequência dos assuntos relacionados à Recursos Humanos e Recursos Materiais na assistência \\
odontológica recebidos pela Ouvidoria SUS Recife no período de 2008 2017-Recife, 2019. \\
\hline Variáveis & $n$ & $\%$ \\
\hline & & \\
Recursos Humanos & 154 & 52,0 \\
\hline Falta de trabalhador & 70 & 23,6 \\
\hline Insatisfação & 44 & 14,8 \\
\hline Trabalhador em saúde bucal & 12 & 4,0 \\
\hline Satisfação & 6 & 2,0 \\
\hline Falta de profissional & & \\
\hline
\end{tabular}




\begin{tabular}{|l|c|c|}
\hline Carga horária dos profissionais & 5 & 1,6 \\
\hline Contratacão profissional & 2 & 0,6 \\
\hline Greve & 2 & 0,6 \\
\hline Outros & 1 & 0,3 \\
\hline Recursos Materiais & & \\
\hline Equipamento com defeito/falta de equipamento & 8 & 3,3 \\
\hline Materiais/instrumentos/produtos/equipamentos & 11 & 4,6 \\
\hline Material de expediente & 92 & 38,8 \\
\hline Material de uso contínuo/permanente & 126 & 53,1 \\
\hline
\end{tabular}

Fonte: Base de dados da Ouvidoria Municipal de Saúdedo Recife

\section{Ouvidoria como Ferramenta de Gestão}

As ouvidorias municipais de saúde podem funcionar como importante instrumento de gestão, uma vez que indicam as fragilidades dos serviços ofertados, a partir da visão de quem os utiliza, além de ser um instrumento de comunicação entre Estado e sociedade. Todas as manifestações recebidas são relevantes, pois buscam dar significado às situações enfrentadas pelos gestores, e dessa forma, ajudam na tomada de decisão pelos mesmos ${ }^{38}$. Segundo Bonavides ${ }^{39}$, a cidadania é manifestada pela via participativa, através da manifestação da vontade de cada indivíduo. Sendo assim, a possibilidade de poder elogiar, denunciar, solicitar, reclamar, sugerir e pedir informações através da ouvidoria é a manifestação viva do exercício de cidadania.

As formas de controle e participação social são essenciais para garantir a visibilidade e a expressão das demandas da sociedade, democratizando os processos deliberativos e de gestão ${ }^{40}$. Essa visibilidade que as manifestações recebidas fornecem aos gestores foi muito citada durante o grupo focal, sendo considerada uma grande potencialidade da ouvidoria:

"Então eu acho que a ferramenta [a ouvidoria] foi de extrema importância para gente enxergar de uma forma mais prática... e enxergar a forma de resolver. [...] porque, às vezes, a gente está lá [na coordenação] e não está vendo [...] o que está acontecendo, o motivo que levou a pessoa a fazer a queixa ou o elogio. Então, [a ouvidoria] dá visibilidade para gestão ver o que está acontecendo lá na ponta"(C.4).

"[...] a queixa, ela colabora para que a gente olhe com mais cuidado, com mais urgência, para aquela situação que a gente sabe que está em desacordo, que não está ideal. E também é uma forma como a população está enxergando essa ausência... nessa fala de inexistência de serviço e de como a gente pode dar um retorno para população em relação a isso"(C.1).

Destaca-se que as manifestações, quando formalizadas através da ouvidoria, ampliam a voz do cidadão e descrevem a sua percepção sobre a administração pública. Todas as manifestações registradas e legitimadas pela ouvidoria são importantes para subsidiar a tomada de decisão dos 
gestores, além de modificar substantivamente o funcionamento do aparelho estatal e criar bases para viabilizar a participação da sociedade civil na definição e execução das políticas públicas. E, por isso, os gestores devem utilizar as informações para aprimorar os serviços ${ }^{14,41}$.

"[...] a gente acabou tomando uma decisão de gestão em virtude da queixa [demanda da ouvidoria]. Não estava formalizada, mas a gente já ouvia queixa, o zumzumzum que a gente chama. Mas como formalizou, ela [a queixa] conseguiu ter essa visualização e a gente acabou tomando uma decisão de outra maneira" (C.2).

"Eu acho que [a ouvidoria] é um dos pilares do planejamento da gente. A gente vai planejar determinadas ações em virtude dessas demandas [...] A tomada de decisão, ela é a maior potencialidade, para mim, da ouvidoria"(C.2).

É necessário que a ouvidoria seja utilizadafrequentemente e de maneira correta, tanto pelos gestores quanto pelo cidadão que realiza a manifestação. De acordo com a percepção dos entrevistados, a ouvidoria ainda ésubutilizada pelos cidadãos, o que compromete o uso potencial da ouvidoria como uma ferramenta de gestão.

“[...]Dificilmente eles têm esse olhar que a ouvidoria é uma ferramenta para ajudar na gestão. [...] então às vezes eles não sabem utilizar a ferramenta. [...] a população tem muito o que aprender ainda, como usar e de forma coletiva. [...] é, parece que eles não entendem que é uma ferramenta que não é só para reclamação"(C.4).

"[...] eu ainda não tive essa experiência [receber demanda da ouvidoria]. Não porque, provavelmente, não tenham queixas ou elogios. Com certeza tem. Mas, às vezes, a própria população não sabe utilizar esse mecanismo a favor da melhoria dos serviços de saúde" (C.1).

"[...] ouvidoria ainda é subutilizada [...] a gente percebe que a comunidade ainda não se deu conta que poderia usar o instrumento da ouvidoria para fazer a solicitação da resolução do problema. [...] O número de ouvidorias que chega é menos do que o que deveria chegar" (C.3).

Mesmo com a implementação de mecanismos de participação popular, ainda se têm diversos obstáculos que impedem que esses funcionem da maneira proposta, limitando a participação da população. Assim, é importante a divulgação e explanação ao cidadão sobre a importância e competências dos serviços. E, no caso da ouvidoria, sobre sua função de 'ponte' entre o cidadão e a gestão ${ }^{42}$. Segundo Moimaz et al. ${ }^{2}$, a falta de divulgação dos meios de participação e a falta de divulgação das propostas e iniciativas para a comunidadesão condições que levam àbaixa adesão da comunidade aos processos decisórios locais.

\section{CONSIDERAÇÕES FINAIS}

Identificou-se um desconhecimento dos entrevistados sobre o fluxo instalado na Ouvidoria SUS 
Recife, evidenciando fragilidade de comunicação e articulação entre a ouvidoria e os gestores de saúde bucal do município. Quanto ao perfil dos demandantes, constatou-se que mulheres na faixa etária de 30 a 49 anos, com no mínimo o ensino fundamental completo, foram as responsáveis pela realização do maior número das demandas relacionadas à saúde bucal registradas na ouvidoria. Essas demandas representaram um pequeno número do total dasdemandasrecebidas pela ouvidoria no período estudado, sendo as manifestações registradas principalmente como reclamações, seguidas pelas solicitações, geralmente envolvendo recursos humanos.

Destaca-se que a maior potencialidade da ouvidoriaidentificada pelos gestores foi representada pela visibilidade que ela promove das demandas da sociedade, subsidiando a tomada de decisão dos gestorespara aprimorar os serviços. Entretanto, a ouvidoria ainda ésubutilizada pelos cidadãos, o que compromete o uso potencial da ouvidoria como uma ferramenta de gestão.

Por fim, considerando os resultados dessa pesquisa e a escassez da literatura sobre a ouvidoria como ferramenta de gestão alicerçada na participação da comunidade, sugere-se o desenvolvimento de outros estudos para aprofundar essa discussão, contribuindo, assim, para o fortalecimento da democratização de processos deliberativos e de gestão no SUS.

\section{REFERÊNCIAS}

1. Rolim LB, Cruz RSBLC, Sampaio KJAJ. Participação popular e o controle social como diretriz do SUS: uma revisão narrativa. Saúde em Debate [internet]. 2013 [acesso em 2018 ago 20], 37(96):139-147. Disponível em: http://www.scielo.br/pdf/sdeb/v37n96/16.pdf2.

2. Moimaz SAS, Rós DT, Rovida TAS, Garbin CAS. O cidadão usuário do serviço odontológico do Sistema Único de Saúde sabe onde reclamar? O controle social na saúde. J Health Sci Inst. 2015, 33(4):323-7.

3. Vaitsman J, Andrade GRB. Satisfação e responsividade: formas de medir a qualidade e a humanização da assistência à saúde. Ciência \& Saúde Coletiva. 2005, 10(3):599-613.

4. Brasil. Ministério da Saúde. Política Nacional de Gestão Estratégica e Participativa no SUS - ParticipaSUS. Brasília: Ministério da Saúde; 2009.

5. Buvinich DPR. Ouvidoria: uma análise de sua utilização como ferramenta de gestão no âmbito da Agência Nacional de Vigilância Sanitária (Anvisa) [tese]. [Salvador]: Instituto de Saúde Coletiva, Universidade Federal ad Bahia; 2009. 95p.

6. Piterman A, Junior FAT, Leles FA. Ouvidoria de saúde em ação: uma experiência inovadora sobre as práticas dos serviços do SUS. Cadernos Ibero-americanos de Direito Sanitário. 2013, 2(2):160-168.

ISSN 1982-8829 Tempus, actas de saúde colet, Brasília, 13(3), 43-59, set, 2019. Epub Jul/2020 
7. Recife. Secretaria de Saúde do Recife. Plano Municipal de Saúde 2006-2009. Recife:

Secretaria de Saúde do Recife; 2005 [acesso em 2019 mar 17]. Disponível em: https://pt.scribd. com/document/85975522/Plano-Municipal-de-Saude-2006-2009-Recife

8. Mello, CG. Análise do tele-atendimento da ouvidoria municipal do SUS - Recife [Monografia]. [Recife]: Universidade de Pernambuco; 2009. 70p.

9. Recife. Secretaria de Saúde do Recife. Equipe da Ouvidoria do SUS Recife. Recife: Ouvidoria SUS Recife. No prelo 2017.

10. Recife. Secretaria de Saúde do Recife. Plano Municipal de Saúde 2018-2021. Recife: Secretaria de Saúde do Recife. No prelo 2017.

11. Bardin L. Análise de Conteúdo. São Paulo: Edições 70, 2016.

12. Brasil. Ministério da Saúde. Manual de Tipificação do Sistema Informatizado OuvidorSUS. Brasília: Ministério da Saúde; 2017.

13. Brasil. Lei no 13.460 de 26 de julho de 2017. Participação, proteção e defesa dos direitos do usuário dos serviços públicos da administração pública.Diário Oficial da União. 26 jul 2017.

14. Abrantes, CM. As demandas de uma Ouvidoria em saúde e os desafios para a efetividade da gestão participativa [dissertação][internet]. [Niterói]:Escola de Enfermagem Aurora de Afonso Costa, Universidade Federal Fluminense; 2017. 84p. [acesso em 2018 out 13]. Disponível em: https://app.uff.br/riuff/bitstream/1/5954/1/Disserta\%C3\%A7\%C3\%A3o\%20revisada\%20-\%20 Cristiane\%20de\%20Matos\%20Abrantes.pdf

15. Cardoso ASR. Ouvidoria Pública como instrumento de mudança. Brasilia: Instituto de Pesquisa Econômica Aplicada (IPEA); 2010 [acesso em 15 jan 19]. Disponível em: https://www. econstor.eu/bitstream/10419/91021/1/626455022.pdf

16. Assunção MCF, Santo ISS, Gigante DP. Atenção Primária em diabetes no sul do Brasil: estrutura, processo e resultado. Rev. Saúde Pública [internet]. 2001 [acesso em 2018 set 14], 35(1):88-95. Disponível em: http://www.scielo.br/scielo.php?pid=S0034$89102001000100013 \&$ script $=$ sci_abstract\&tlng=pt

17. Vieira AC. Clientelismo e serviços de saúde. Revista de Políticas Públicas. 2002; 6(1):940.

18. Ceará. Secretaria de Saúde do Estado do Ceará. Relatório da Ouvidoria Geral da Secretaria da Saúde do Estado do Ceará. Ceará: Secretaria de Saúde do Estado do Ceará; 2015.

19. Pinto HA, Burille A, Barbosa MG, Ferla AA. Avaliação da Atenção Básica: A Ouvidoria Tempus, actas de saúde colet, Brasília, 13(3), 43-59, set, 2019. Epub Jul/2020 ISSN 1982-8829 
Ativa como Estratégia de Fortalecimento do Cuidado e da Participação Social. Saúde em Redes. 2015, 4(1):15 - 26 .

20. Brasil. Ministério da Saúde. Relatório Gerencial. Brasília: Secretaria de Gestão Estratégica e Participativa; 2016.

21. Ribeiro MCSA, Barata RB, Almeida MF, Silva ZP. Perfil sociodemográfico e padrão de utilização de serviços de saúde para usuários e não-usuários do SUS - PNAD 2003. Ciência \& Saúde Coletiva. 2006, 11(4):1011-1022.

22. Pereira LH. A voz do usuário no sistema hospitalar: ouvidorias. Sociologias [internet], 2002 [acesso em 2018 set 25), 4(7):82-121. Disponível em: http://www.scielo.br/pdf/soc/n7/ a04n7.pdf

23. Fernandes LCL, Bertoldi AD, Barros AJD. Utilização dos serviços de saúde pela população coberta pela Estratégia de Saúde da Família. Revista de Saúde Pública [internet]. 2009 [acesso em 2018 ago 5], 43(4): 595-603. Disponível em: http://www.scielo.br/scielo. php?pid=S0034-89102009005000040\&script $=$ sci_abstract\&tlng $=$ pt

24. Felchilcher E, Araújo G, Traverso MED. Perfil dos Usuários de uma Unidade Básica de Saúde do Meio-Oeste Catarinense. Unoesc \& Ciência [internet]. 2015 [acesso em 2018 ago 5], 6(2):223-30. Disponível em: https://editora.unoesc.edu.br/index.php/acbs/article/view/7919/pdf

25. Magnago RF, Moreira DS, Cunha L, Sake TM. Perfil dos usuários do posto de saúde da família do bairro Humaitá, Tubarão - SC. Arquivos Catarinenses de Medicina [internet]. 2009 [acesso em 2018 ago 7], 30(2):12-20. Disponível em: http://www.acm.org.br/revista/pdf/ artigos/731.pdf

26. Pimentel IRS, Coelho BC, Lima JC, e outros. Caracterização da demanda em uma Unidade de Saúde da Família. Revista Brasileira de Medicina de Família e Comunidade [internet], 2011 [acesso em 2018 out 10], 6(20):175-181. Disponível em: https://rbmfc.org.br/rbmfc/article/ viewFile/95/364

27. Kilsztajn S, Rossbach A, Camara MB, e outros. Serviços de Saúde, Gastos e Envelhecimento da População Brasileira. In: XIII Encontro da Associação Brasileira de Estudos Populacionais, 2002; Ouro Preto: Laboratório de Economia Social do Programa de Estudos PósGraduados em Economia Política - LES/PUCSP; 2002 [acesso em 16 jan 19]. Disponível em: http://www.abep.org.br/publicacoes/index.php/anais/article/viewFile/1252/1216

28. Machion L, Freitas PM, Cesar Neto JB, e outros. A influência do sexo e da idade na prevalência de bolsas periodontais. Pesq Odont Bras [internet], 2000 [acesso em $13 \mathrm{fev}$ 19], 14(1):33-37. Disponível em: http://www.scielo.br/pdf/\%0D/pob/v14n1/v14n1a05.pdf 
29. Silva AL, Saintrain MVL. Interferência do perfil epidemiológico do idoso na atenção odontológica. Rev Bras Epidemiol [internet], 2006 [acesso em 13 fev 2019], 9(2): 242-50. Disponível em: http://www.scielo.br/pdf/rbepid/v9n2/11.pdf

30. Barbato PR, Nagano HCM, Zanchet FN, e outros. Perdas dentárias e fatores sociais, demográficos e de serviços associados em adultos brasileiros: uma análise dos dados do Estudo Epidemiológico Nacional (Projeto SB Brasil 2002-2003). Cad. Saúde Pública [internet], 2007 [acesso em 13 fev 2019], 23(8):1803-1814. Disponível em: https://www.scielosp.org/pdf/ csp/2007.v23n8/1803-1814/pt

31. Veras MMS. A Satisfação dos Usuários do SUS com o Serviço de Ouvidoria em Saúde de Fortaleza-CE [dissertação] [internet]. [Fortaleza]: Universidade Federal do Ceará; 2005, 158p. [acesso em 2018 nov 10] Disponível em: http://www.ipea.gov.br/participacao/images/ dissertacaomirellaveras.pdf

32. Silva ZP, Ribeiro MCSA, Barata RB, Almeida MF. Perfil sociodemográfico e padrão de utilização dos serviços de saúde do Sistema Único de Saúde (SUS), 2003- 2008. Ciência \& Saúde Coletiva. 2011, 19(6):3807-3816.

33. Duarte D, Eble LJ, Garcia LP. 30 anos do Sistema Único de Saúde. Epidemiol. Serv. Saúde[internet]. 2018 [acesso em 2018 ago 5], 27(1). Disponível em: http://scielo.iec.gov.br/ scielo.php?script=sci_arttext\&pid=S1679-49742018000100001

34. Mario CG. Ouvidorias Públicas Municipais no Brasil [dissertação]. [Campinas]: Pontifícia Universidade Católica de Campinas; 2006. 146p.

35. Peixoto SF, Marsiglia RMG, Morrone LC. Atribuições de uma ouvidoria: opinião de usuários e funcionários. Revista Saúde Soc. 2013, 22(3):785-94.

36. Silva RSP. O entendimento do direito à saúde: uma abordagem dos usuários do SUS no Distrito Federal. Cad. Ibero-Amer. Dir. Sanit [internet]. 2015 [acesso em 16 jan 19], 4(3):56-74. Disponível em: https://www.cadernos.prodisa.fiocruz.br/index.php/cadernos/article/view/156/364

37. Lima GCPO. Perfil dos Usuários que Acessaram a Ouvidoria do Sus, no Distrito Sanitário VI do Recife, em 2010 [monografia] [internet]. [Recife]: Centro de Pesquisas Aggeu Magalhães da Fundação Oswaldo Cruz;2011, 21p. [acesso em 2018 nov 25]. Disponível em: http://www. cpqam.fiocruz.br/bibpdf/2011lima-gcpo.pdf

38. Souza RCR, Soares E, Cordeiro CEM, Gomes NL, e outros. Percepção dos usuários sobre o serviço de ouvidoria em saúde: pesquisa descritiva. Online Brazilian Journal of Nursing [internet] 2012 [acesso em 2018 nov 26], 11(30):751-62. Disponível em:http://www.objnursing. uff.br/index.php/nursing/article/viewFile/3631/pdf 
39. Bonavides PA.Constituição Aberta - Temas políticos e constitucionais da atualidade, com ênfase no Federalismo das Regiões. São Paulo: Malheiros, 2004.

40. Brasil. Controladoria Geral da União. Orientações para o Atendimento ao cidadão nas ouvidorias públicas — rumo ao sistema participativo. Brasília: Controladoria Geral da União; 2012.

41. Chassot JP. A Participação Social na Gestão de Políticas Públicas no Município de Ijuí Uma Análise da Experiência Local [monografia] [internet]. Santa Maria: Universidade Federal de Santa Maria; 2013. 16p. [acesso em 2018 nov 13]. Disponível em: https://repositorio.ufsm.br/ bitstream/handle/1/248/Chassot_Jean_Pierre.pdf?sequence $=1$

42. Oliveira IM. Ouvidoria: Um estudo junto à Secretaria Municipal de Saúde do Recife [monografia] [internet]. [Recife]: Faculdade Boa Viagem; 2007. 34p. [acesso em 2019 jan 28]. Disponível em: http://www.dhnet.org.br/direitos/militantes/rubenspinto/a_pdf/mono_izabela_ oliveira_ouvidoria_um_estudo.pdf

Artigo apresentado em outubro de 2019 Artigo aprovado em março de 2020 Artigo publicado em julho de 2020 